\title{
Parameters of Right Ventricle as etiological distinction between ischemic and non-ischemic dilated cardiomyopathy
}

\author{
Hélder Andrade Gomes*, Mariana M Lamacié, Fábio V Fernandes, Bernardo N Abreu, Matheus D Freitas, \\ Paulo C Dias Filho, Valéria Moreira, Adriano Carneiro, Tiago A Magalhães, Carlos E Rochitte
}

From 18th Annual SCMR Scientific Sessions

Nice, France. 4-7 February 2015

\section{Background}

Dilated left ventricular volumes (VE) is one of the main factors of poor cardiovascular prognosis with systolic dysfunction. Myocardial fibrosis detected by late gadolinium enhancement (LGE) on cardiac magnetic resonance (CMR) has been recognized in recent years as an independent prognostic factor in dilated cardiomyopathy, in addition to guiding the etiological diagnosis, and most often the only noninvasive way to differentiate ischemic and nonischemic. The aim of our study was to determine the prevalence of myocardial fibrosis in patients with dilated LV and the morphological and functional differences between ischemic and non-ischemic patterns.

\section{Methods}

We analyzed 114 consecutive patients $\geq 35$ years old who were undergoing CMR with $\mathrm{LV}$ volume $\geq 95 \mathrm{ml} /$ m2 between March/2013 and August/2014. After identifying the prevalence of myocardial fibrosis, we analysed the morphological and functional differences between patients with ischemic pattern of LGE and non-ischemic pattern of LGE.

\section{Results}

Patients were $57 \pm 11$ years old, BMI $=27.6 \pm 5.0 \mathrm{~kg} / \mathrm{m} 2$, LVEF $=43 \pm 17 \%$, RVEF $=57 \pm 13 \%$ and $81 \%$ male. Sixtytwo (54\%) had myocardial fibrosis by LGE, including 36 (58\%) with ischemic pattern and $25(40 \%)$ with nonischemic pattern, and one patient was excluded for presenting the two types of LGE. Among patients with myocardial fibrosis, those who exhibited a pattern of nonischemic LGE had worse RVEF ( $50 \pm 16 \%$ vs $62 \pm 9 \%$, p =
$0.003)$ and greater RV volumes (RVEDVI/RVESVI $72 \pm 21 /$ $36 \pm 18$ vs $59 \pm 15 / 22 \pm 8 \mathrm{ml} / \mathrm{m} 2, \mathrm{p}=0.012 / 0.001$ ), with no significant differences in age, sex, BMI, parameters of LV (volumes and $\mathrm{EF}$ ) or heart rate during CMR performance. Regarding the number of LV segments affected by fibrosis, ischemic patients had more extensive disease $(7.1 \pm 4.2$ vs $3.7 \pm 3.2$ segments, $\mathrm{p}=0.001$ ).

\section{Conclusions}

Patients with non-ischemic myocardial fibrosis pattern had higher RV volumes and worse RVEF, and myocardial fibrosis in fewer number of LV segments compared to ischemic pattern. Volumes and EF preserved RV might suggest ischemic etiology in patients under investigation for dilated cardiomyopathy.

Table 1

\begin{tabular}{cccc}
\hline & Ischemic & non-ischemic & $p$ \\
\hline Patients & $36(59 \%)$ & $25(41 \%)$ & NA \\
\hline Age, yo & $62 \pm 10$ & $59 \pm 10$ & 0.229 \\
\hline Gender, male (\%) & $32(89 \%)$ & $19(76 \%)$ & 0.214 \\
\hline BMI & $27.7 \pm 4.2$ & $28.1 \pm 4.7$ & 0.765 \\
\hline HR & $68 \pm 14$ & $69 \pm 12$ & 0.732 \\
\hline LVEF & $36 \pm 14$ & $39 \pm 18$ & 0.493 \\
\hline LVEDVI & $130 \pm 44$ & $125 \pm 34$ & 0.645 \\
\hline LVESVI & $86 \pm 46$ & $81 \pm 44$ & 0.637 \\
\hline RVEF & $62 \pm 9$ & $50 \pm 16$ & $0.003^{*}$ \\
\hline RVEDVI & $59 \pm 15$ & $72 \pm 21$ & $0.012^{*}$ \\
\hline RVESVI & $22 \pm 8$ & $36 \pm 18$ & $0.001^{*}$ \\
\hline Segments with LGE & $7.1 \pm 4.2$ & $3.7 \pm 3.2$ & $0.001^{*}$ \\
\hline *p $<0.05$ & & &
\end{tabular}

Hospital do Coração, São Paulo, Brazil 


\section{Funding}

None.

Published: 3 February 2015

doi:10.1186/1532-429X-17-S1-P311

Cite this article as: Gomes et al: Parameters of Right Ventricle as etiological distinction between ischemic and non-ischemic dilated cardiomyopathy. Journal of Cardiovascular Magnetic Resonance 201517 (Suppl 1):P311.

Submit your next manuscript to BioMed Central and take full advantage of:

- Convenient online submission

- Thorough peer review

- No space constraints or color figure charges

- Immediate publication on acceptance

- Inclusion in PubMed, CAS, Scopus and Google Scholar

- Research which is freely available for redistribution 